\title{
Analisis Pengetahuan Masyarakat Tentang Resiko Bahaya Hipertensi
}

\author{
Vevi Kurniawati \\ Akademi Keperawatan Kesdam I/Bukit Barisan Padang \\ Email : vevikurniawati444@gmail.com
}

\begin{abstract}
ABSTRAK
Hipertensi adalah salah satu penyakit kardiovaskular yang menyebabkan angka kematian tertinggi. Di Indonesia Prevalensi hipertensi tahun 2013 menempati urutan pertama yang dialami oleh orang dewasa, yaitu sebesar 26,5\%. Kota Padang memiliki angka kejadian 52.825 jiwa. Dan sampai saat ini prevalensi kejadian masih terus tinggi, jadi untuk mengatasinya tentunya harus didukung oleh pengetahuan yang baik terkait dengan resiko bahaya hipertensi agar masyarakat dapat mengantisipasi agar terhindar dari dampak hipertensi. Tujuan penelitian ini untuk mengetahui pengetahuan masyarakat tentang resiko bahaya hipertensi diwilayah kerja Puskesmas Rawang Tahun 2019. Untuk Pengambilan menggunakan teknik random sampling. Dari 30 sampel masyarakat yang pengetahuanya baik adalah sebanyak 19 orang $(63,4 \%)$ dan pengetahuan kurang baik sebanyak 11 orang $(36,6 \%)$. Kesimpulan penelitian ini adalah pengetahuan masyarakat tentang resiko bahaya hipertensi adalah baik.
\end{abstract}

Kata Kunci : Pengetahuan, resiko, hipertensi.

\begin{abstract}
ABSTRAK
Hypertension is a cardiovascular disease that causes the highest mortality rate. In Indonesia the prevalence of hypertension in 2013 was taken first which was attended by adults, which was $26.5 \%$. In West Sumatra in 2016 the incidence of 248,964 people, in the city of Padang in 2017 the incidence of hypertension reached 52,825 people. And until now the prevalence of the incidence remains high with the number of hypertensive sufferers in 2018 is 150, 591 people. To overcome this must be approved by knowledge related to the risk of hypertension so that people can avoid to avoid hypertension. This study aims to study public knowledge about the risk of hypertension in the working area of Rawang Health Center in 2019. The research method used was a survey method using random sampling techniques. The results obtained by people who have good knowledge as many as 19 people (63.4\%) and poor knowledge as many as 11 people (36.6\%). The conclusion of this study is public knowledge about the dangers of good hypertension.
\end{abstract}

Keywords: Knowledge, risk, hypertension.

\section{PENDAHULUAN}


Hipertensi merupakan suatu keadaan dimana terjadinya gangguan sistem peredaran darah yang menyebabkan kenaikan tekanan darah diatas batas normal yaitu sistolik $\geq 140$ $\mathrm{mmHg}$ dan diastolik $\geq 90 \mathrm{mmHg}$ atau yang juga dikenal dengan tekanan darah tinggi. Menurut WHO (Word Health Organization), Bila tekanan darah sudah lebih dari 140/90 mmHg dinyatakan hipertensi, batas tersebut untuk orang dewasa di atas 18 tahun. Penderita hipertensi ini sudah dimulai sejak usia $\geq 18$ tahun (Adib, 2009).

Data World Health Organization (WHO) pada tahun 2015 menunjukkan sekitar 1,13 Miliar orang di Dunia menderita hipertensi, artinya 1 dari 3 orang di Dunia terdiagnosis hipertensi. Jumlah penderita hipertensi ini terus meningkat setiap tahunnya, dan diperkirakan pada tahun 2025 akan ada 1,5 Miliar orang yang terkena hipertensi, dan diperkirakan setiap tahunnya 9,4 juta orang meninggal akibat hipertensi dan komplikasinya (Kemenkes RI, 2019). Berdasarkan data laporan Riskesdas tahun 2013, prevalensi hipertensi di Indonesia menempati urutan pertama jenis penyakit kronik tidak menular yang dialami oleh orang dewasa, yaitu sebesar $26,5 \%$.

Penderita hipertensi di Sumatera Barat tahun 2016 sebanyak 248.964 jiwa, atau sebesar $13,8 \%$. Berdasarkan data yang didapat dari Dinas Kesehatan Kota Padang tahun 2016, dengan angka kejadian hipertensi sebanyak 47.902 jiwa dan pada tahun 2017 angka kejadian hipertensi meningkat menjadi 52.825 jiwa $(9,31 \%)$. Sampai saat ini prevalensi kejadian masih tinggi dengan jumlah estimasi penderita hipertensi tahun 2018 adalah 150, 591 jiwa (Dinkes, 2018).

Penderita Hipertensi dijumpai di dalam masyarakat dengan jumlah penderita yang terus meningkat setiap tahunnya. Salah satunya adalah di wilayah kerja puskesmas rawang Padang. Berdasarkan hasil wawancara pada pengunjung puskesmas yang dilakukan pada survey awal, didapatkan masih banyak pengunjung yang mempunyai keluhan terhadap tekanan darah yang tinggi.

Penyakit Hipertensi dapat timbul akibat adanya interaksi berbagai faktor resiko yang dimiliki seseorang. Banyak faktor yang dapat mempengaruhi hipertensi, baik faktor yang dapat dikontrol maupun tidak. Faktor yang tidak dapat dikontrol seperti riwayat keluarga, jenis kelamin, dan umur. Sementara, faktor yang dapat dikontrol seperti pola konsumsi makanan yang mengandung natrium, lemak, perilaku merokok, obesitas, dan kurangnya aktivitas fisik (Anggraini dkk, 2008). Ginting (2008) juga menegaskan bahwa faktor yang dapat mempengaruhi tekanan darah yang dapat dikontrol adalah pola hidup, dimana pola hidup seseorang sangat dipengaruhi oleh pengetahuannya akan suatu penyakit.

Hipertensi yang terjadi dalam kurun waktu yang lama akan berbahaya sehingga menimbulkan komplikasi. Komplikasi tersebut dapat menyerang berbagai target organ tubuh yaitu otak, mata, jantung, pembuluh darah arteri, serta ginjal (Marliani, 2007). Sebagai dampak terjadinya komplikasi hipertensi, kualitas hidup 
penderita menjadi rendah dan kemungkinan terburuknya adalah terjadinya kematian pada penderita akibat komplikasi hipertensi yang dimilikinya (Ramitha. 2008).

Penderita hipertensi ini tidak merasakan dan menyadari tanda dan gejala yang spesifik bila sudah terjadi komplikasi seperti jantung, stroke, atau kerusakan ginjal. Oleh karena itu penyakit ini sering disebut silent killer (Tryanto, 2014). Seseorang perlu menjalankan pola hidup sehat secara umum untuk dapat menurunkan resiko permasalahan kardiovaskular yang akan muncul (Dipiro, dkk., 2011; Soenarta, dkk., 2015).

Beberapa pola hidup sehat yang dianjurkan di antaranya penurunan berat badan yang berlebih, mengurangi asupan garam, olahraga, mengurangi konsumsi alkohol, dan berhenti merokok (Dipiro, dkk., 2011; Soenarta, dkk., 2015). Maryam, et al (2008) menegaskan bahwa faktor resiko yang dapat menyebabkan hipertensi yaitu faktor genetik, umur, jenis kelamin, obesitas, asuhan garam, konsumsi alkohol, dan kebiasaan merokok.

Munculnya masalah kesehatan seperti halnya hipertensi ini, tidak hanya disebabkan oleh kelalaian individu, namun dapat pula disebabkan oleh ketidaktahuan masyarakat sebagai akibat dari kurangnya informasi yang benar mengenai suatu penyakit (Rahmadiana, 2012 ; Kusuma RS, 2017). Rendahnya pengetahuan masyarakat tentang hipertensi merupakan penyebab utama tidak terkontrolnya tekanan darah
(Park, J.B., Kario, K., dan Wang, J.G., 2015).

Berdasarkan uraian diatas, maka perlu dilakukan penelitian tentang pengetahuan masyarakat terhadap resiko bahaya hipertensi. Penelitian ini bertujuan untuk mengetahui pengetahuan masyarakat tentang resiko bahaya hipertensi di wilayah kerja Puskesmas Rawang Padang.

\section{METODE PENELITIAN}

Metode penelitian yang digunakan dalam penelitian ini adalah metode survei. Pengambilan sampel dalam penelitian ini menggunakan teknik simple random sampling dengan sampel penelitian sebanyak 30 responden. Populasi pada penelitian ini adalah pengunjung Puskesmas Rawang.

\section{HASIL}

Berdasarkan hasil penelitian yang telah dilakukan terhadap 30 responden, didapatkan hasil sebagai berikut:

Tabel 1. Karakteristik Responden

\begin{tabular}{|c|c|c|c|}
\hline \multirow{2}{*}{\multicolumn{4}{|c|}{$\begin{array}{ll}\text { No. } & \text { Kategori } \\
1 . & \text { Umur } \\
\end{array}$}} \\
\hline & & & \\
\hline & $18-35$ th & 8 & 26,7 \\
\hline & $36-60$ th & 22 & $\underline{73,3}$ \\
\hline \multirow[t]{3}{*}{2.} & Jenis Kelamin & & \\
\hline & Laki - laki & 13 & 43,3 \\
\hline & Perempuan & 17 & $\underline{56.7}$ \\
\hline \multirow[t]{4}{*}{3.} & Pendidikan & & \\
\hline & Pendidikan dasar & 2 & 6,7 \\
\hline & Pendidikan menengah & 22 & 73,3 \\
\hline & Pendidikan Tinggi & 6 & 20 \\
\hline \multirow[t]{2}{*}{4.} & $\begin{array}{l}\text { Sumber informasi } \\
\text { tentang hipertensi }\end{array}$ & & \\
\hline & Keluarga & 10 & 33,3 \\
\hline
\end{tabular}




\begin{tabular}{lll} 
Pelayanan Kesehatan & 11 & 36,7 \\
Media Massa & 4 & 13,3 \\
Lain - lain & 5 & 16,7 \\
Tidak pernah & 0 & \\
\hline
\end{tabular}

Berdasarkan tabel yang telah dipaparkan di atas menyatakan bahwa dari kategori usia distribusi frekuensi yang paling banyak menderita hipertensi adalah umur 36 - 60 tahun yang berjumlah 22 responden $(73,3 \%)$. Kategori jenis kelamin paling banyak adalah perempuan sebanyak

17 responden $(56,7 \%)$. Pendidikan masyarakat didominasi oleh tingkat Pendidikan menengah sebanyak 22 responden (73,3\%). Sumber informasi tentang hipertensi yang paling banyak adalah dari pelayanan kesehatan berjumlah 11 responden $(36,7 \%)$.

Tabel 2. Pengetahuan Masyarakat Tentang Resiko Bahaya Hipertensi

\begin{tabular}{llll}
\hline No. & Pengetahuan & f & $\%$ \\
\hline 1. & Baik & 19 & 63,4 \\
2. & Kurang & 11 & 36,6 \\
\hline
\end{tabular}

Berdasarkan tabel di atas menunjukkan bahwa sebagian besar pengetahuan masyarakat tentang resiko bahaya hipertensi adalah baik yaitu sebanyak 19 responden $(63,4 \%)$.

\section{PEMBAHASAN}

\section{Pengetahuan Masyarakat tentang Resiko Bahaya Hipertensi}

Berdasarkan hasil penelitian yang telah didapatkan pada tabel 2 bahwa pengetahuan masyarakat tentang resiko bahaya hipertensi berada dalam kategori baik yaitu 63,4\% dan $36,6 \%$ kurang baik. Hal ini menunjukkan bahwa masyarakat di wilayah kerja Puskesmas Rawang, sudah mengetahui dengan baik tentang resiko bahaya hipertensi.

Hasil penelitian ini sesuai dengan penelitian yang diteliti oleh Wardani, Ni Putu (2017) yang meneliti tentang gambaran tingkat pengetahuan hipertensi pada pasien rawat jalan disalah satu rumah sakit yang menyatakan bahwa sebagian besar pasien rawat jalan memiliki tingkat pengetahuan yang baik tentang hipertensi.

Pengetahuan adalah sebuah hasil dari tahu setelah seseorang melakukan penginderaan terhadap suatu obyek tertentu. Pengetahuan sangat berpengaruh dalam pembentukan sikap seseorang. Pengetahuan seorang individu dipengaruhi oleh banyak faktor antara lain tingkat pendidikan, sumber informasi, dan pengalaman yang dapat diperoleh dari diri sendiri maupun orang lain (Notoatmojo, S, 2012).

Hasil penelitian ini juga didukung oleh Hasil penelitian yang telah dilakukan Caroline dkk (2018) mengenai gambaran pengetahuan tentang hipertensi yaitu dari 58 responden menunjukan bahwa sebagian besar responden memiliki pengetahuan baik dengan jumlah 31 responden $(54,4 \%)$.

Pengetahuan responden yang baik dapat diperoleh dari berbagai cara, dapat diperoleh dari diri sendiri yang mendapat informasi dari orang lain secara visual, audio maupun audio-visual. Selain itu juga pengetahuan dapat diperoleh seseorang melalui pengalaman penderita (Angkawijaya, 2016). 
Hal ini dipertegas oleh Notoatmodjo pada tahun 2012 yang menyatakan bahwa pengetahuan seseorang dipengaruhi oleh pengalaman, yang mana dapat diperolah dari pengalaman diri sendiri maupun orang lain, sebagai contoh, jika seseorang pernah merawat anggota keluarga dengan hipertensi pada umumnya menjadi lebih tahu tindakan yang harus dilakukan jika terkena hipertensi (Notoatmodjo, S, 2012).

Seseorang dengan riwayat keluarga hipertensi berisiko mengalami hipertensi. Hipertensi sangat dipengaruhi oleh genetik yang diperburuk oleh faktor kontribusi lainnya. Hal ini dipertegas oleh Situmorang (2015) bahwa faktor - faktor yang berhubungan dengan kejadian hipertensi adalah Faktor genetik, Faktor pola makan, Faktor merokok dan Faktor alkohol.

Responden dengan riwayat hipertensi dari orangtua maupun diri sendiri sebaiknya memiliki pengetahuan yang baik tentang hipertensi agar dapat mencegah terjadinya penyakit ataupun menghambat komplikasi lebih lanjut (Notoatmodjo, S, 2012).

\section{KESIMPULAN}

Berdasarkan hasil penelitian yang telah dilakukan, maka dapat ditarik kesimpulan bahwa pengetahuan masyarakat di wilayah kerja Puskesmas Rawang tentang resiko bahaya hipertensi berada pada kategori baik dengan persentase sebanyak $63,4 \%$.

\section{SARAN}

Penelitian ini bersifat deskriptif dan dengan responden yang relatif sedikit, sehingga hanya menggambarkan hasil penelitian yang sederhana, untuk itu, agar penelitian lanjutan menggunakan jumlah responden yang lebih besar dan dengan cakupan wilayah kerja yang lebih luas, serta dapat menambah variabel penelitian dengan menghubungkan pengetahuan dan sikap responden.

\section{DAFTAR PUSTAKA}

Adib., M,. 2009. Cara Mudah Memahami dan Menghindari Hipertensi Jantung dan Stroke. Dianloka Dianloka Pustaka Populer : Yogyakarta.

Angkawijaya, A. A. 2016. Hubungan tingkat pengetahuan masyarakat dengan tindakan pencegahan hipertensi di Desa Motoboi Kecil Kecamatan Kotamobagu Selatan : JKKT Vol. 4 No. 1

Anggraini, dkk. 2008. Faktor-faktor yang Berhubungan dengan Kejadian Hipertensi pada Pasien yang Berobat di Poliklinik Dewasa Puskesmas Bangkinang Periode Januari sampai Juni 2008 [internet]. c2009 [cited 2015 Nov 25]. Available from http://yayanakhyar.files.wordpress.co $\underline{m} / 2009 /$

Caroline, dkk. 2018. Hubungan Pengetahuan tentang Hipertensi dengan Prilaku Pencegahan 
Kekambuhan Hipertensi pada Lansia. Riau : FK Universitas Riau.

Dinas Kesehatan Kota Padang. 2018. Profil Kesehatan Tahun 2018 : Padang.

Ginting, M. 2008. Determinan tindakan masyarakat dalam pencegahan penyakit hipertensi di Kecamatan Belawan. Medan : USU.

Kemenkes RI. 2019. Hipertensi Penyakit Paling Banyak diidap masyarakat. Biro Komunikasi dan Pelayanan Masyarakat. Dipublikasikan Pada : Jumat, 17 Mei 2019.

Kusuma RS, Erica. 2017. Peningkatan Pengetahuan tentang Hipertensi Guna Perbaikan Tekanan Darah pada Anak Muda di Dusun Japanan. Margodadi, Sayegan, Sleman, Yogyakarta. JPKM, Vol. 3, No. 1, Hal $26-38$.

Marliani, Lili. 2007. 100 Question \& Answers Hipertensi. Jakarta: Elex Media Komputindo.

Maryam, S., Ekasari, M. F., Rosidawati., Jubaedi, A., \& Batubara, I. 2008. Mengenai usia lanjut dan perawatannya. Jakarta: Salemba Medika.

Notoatmojo, S. 2012. Promosi kesehatan dan ilmu perilaku. Jakarta : Rineka Cipta.
Park, J.B., Kario, K., dan Wang, J.G. 2015. Systolic Hypertension: an Increasing Clinical Challenge in Asia" dalam Hypertension Research. Volume 38 (4). Hlm. 227-236.

Ramitha, Vina. 2008. Penderita Hipertensi Harus Disiplin. http://www.inilah.com/berita/2008/0 8/16/44252/upenderitahipertensiharus-disiplin diakses pada tanggal 31-8-2010 pukul 2:38pm

Soenarta, A.A., dkk. 2015. Pedoman Tata Laksana Hipertensi pada Penyakit Kardiovaskular. Pedoman Tata Laksana Hipertensi pada Penyakit Kardiovaskuler. Vol 1. Hlm. 1-2.

Situmorang, P.R. 2015. Faktor-Faktor yang Berhubungan dengan Kejadian Hipertensi pada Penderita Rawat Inap di Rumah Sakit Umum Sari Mutia Medan Tahun 2014. Jurnal Ilmiah Keperawatan Imelda : Vol. 1 No. 1 hal. 71-74.

Triyanto, E. 2014. Pelayanan keperawatan bagi penderita hipertensi secara terpadu. Yogyakarta: Graha Ilmu.

Wardani, Ni Putu. 2017. Gambaran Tingkat Pengetahuan Tentang Hipertensi pada Pasien Rawat Jalan Rumah Sakit Universitas Udayana Kabupaten Bandung. Unit Promosi Kesehatan Rumah Sakit, Bandung. 